\title{
List of Plants collected in Kumamoto \\ Prefecture (Kyüshü) 1895-96.
}

(Continued from p. 11.)

By

H. Nakagawa.

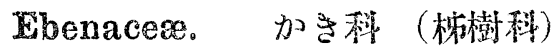

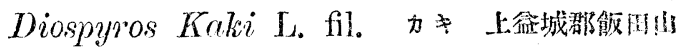

Plumbaginace®. いそまつ程 (磯松程)

Statice japonica Sieb. et Z Zuce. ハマサシ 天草郡篦阿

Primulacea。さくらさう科(櫻草科)

Lysimachia clethroides Duby. キカトラフタ 金峰山 $I$. davurica

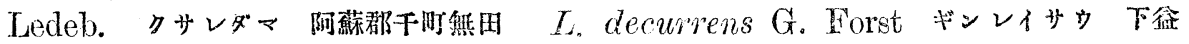
城郡酯碈用村字三少岩 L. japonica Thumb.

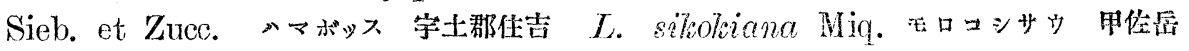

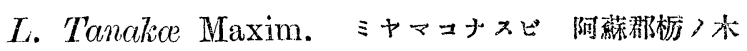

Myrsinaceæ。やぶかうじ科（紧金牛科）

Ardisia japonica Bl. ヤブカッシ 下湓城郡七㿟次官标 A. hortorum

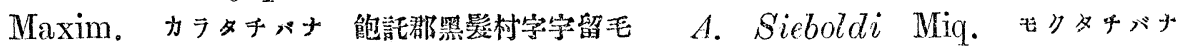

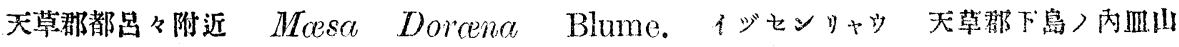
Myrsine capitellata Wall. タイミンタチバ（カメロリつキ）天草郡䋹連水村

Ericaceæ. しゃくな科 (石南科)

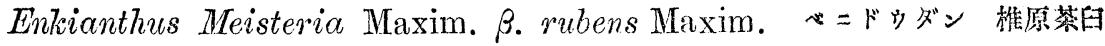

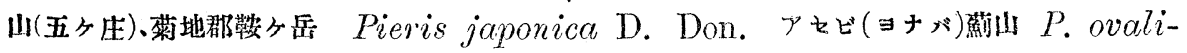
folia D. Don. 子ダギ 鮑託都三八岳 Rhododendron dilatatum Miq. ミ步バ ッ・シ 天草郡福連木村 $R h$. indicum Sweet $\alpha$. Kcempferi Maxim. ヤマッ・シ 下益城郡西砥用村 Rh. Keiskei Miq. 七カダッ、シ 下益城郡洞タ后 Rh. Metternichii Sieb. et Zucc. シャクナが 山大岳(五ヶ生) Rh.rhombicum Miq. コベ

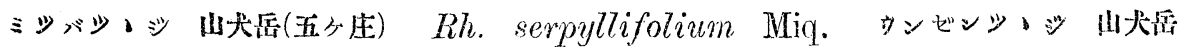
（五方生） Rh. Losaense Makino. フヂッ・阿萑仙 Tripetaleia paniculata

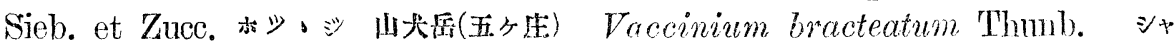

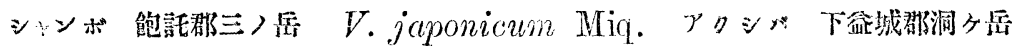




\section{Pyrolaceæ. いちやくさう科（鹿路草科）}

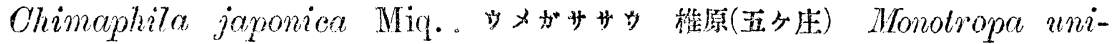

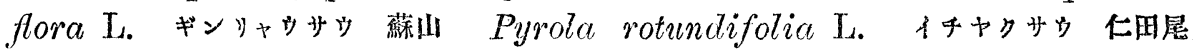
（五公庄）

\section{Clethraceæ. b的ぶ（命法科）}

Clethra barbinervis Sieb. et Zucc. リャリブ 椎原(五ヶ俚)

\section{ARCHICHLAMYDEAE}

\section{Cornaceほ。 みづき科（山荣莫科）}

Aucuba japonica Thunb. ア米 飽託郡二八岳 Cornus brachypoda C. A. Mey. クマノミッ゙キ(カタミッシタ)下谷城郡衡山 C. Kousa Buerg. ヤマバッシ

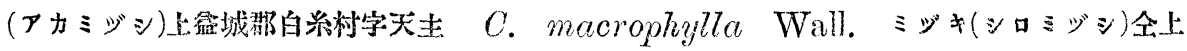
Marlea platanifolia Sieb. et Zucc. ウリノキ(コプリーギ)上益城郡白系村字昆平

\section{Umbelliferæ. 繳形科}

Angelica kiusiana Maxim. ハマシド 宇士郡住吉 A. polymorpla

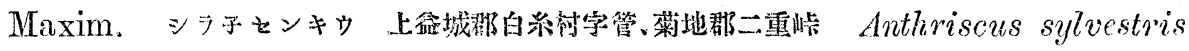

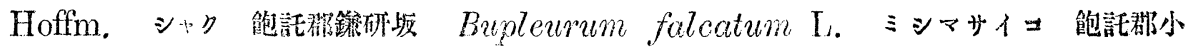

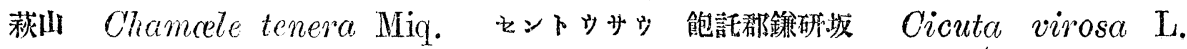

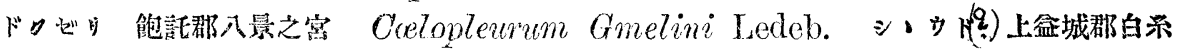
村字管 Cryptotenia canadensis DC. var. japonica Makino. ミ步飽託郡 金峰山 Heracleum lanatum Michx. ハナシド阿蘇郡疠ノ木 Hydrocotyle

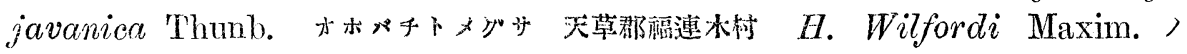
ヂトメ 饱託郡金峰川 Encnthe stolonifera DC. 女り 飽䚾郡本妙寺山 Osmo-

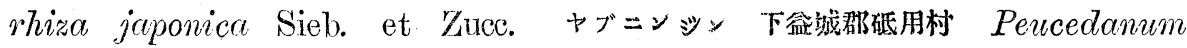

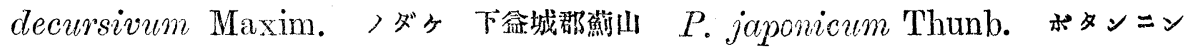
シン 天草郡下津深江 P. cartilayinoserratum Makino MSS. ヒメノダゥ 阿蘇郡赤 瀨ヨり尾名石）間、㐘地郡二重峠 Pimpinella calycina Maxim, カフリメサウ 八代 郡五ケ庄〉內葉木 P. diversifolia DC. ミッバグサ 能託郡本运寺山 Sanicula

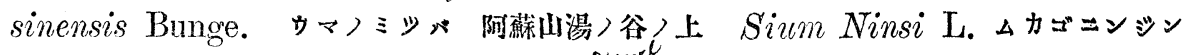
阿葆郡千时無田 Torilis Anthriscus Seop.

\section{Araliaceæ. うこざ科 (五加科)}

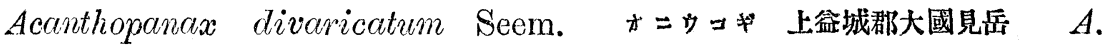
ricinifolium Seem. メリギ 能託郡金峰山 A. scicadphylloides Fr. et Sav.

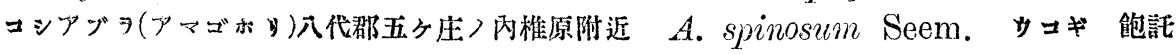

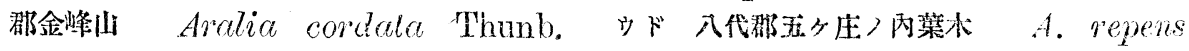

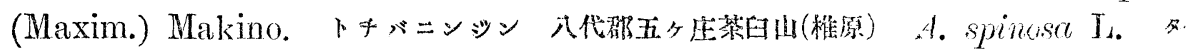

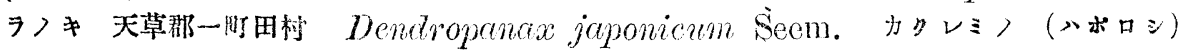




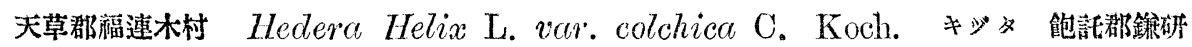

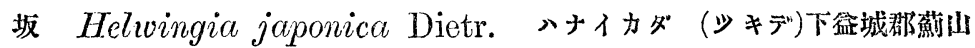

\section{Halorrhagidaceæ. ありのてふ科 (蟻塔科)}

Haloragis micrantha R. Br. ฯッフタフグザ 天草郡福連林 Myriophyllum spicatum L. ホネ゙キフフサモ 字土郘字山附近

\section{Hydrocaryaceæ. ひし科（荠科）}

Trapa incisa Sieb. et Zucc. 七メビシ 上益城郡浮島

\section{Onagraceæ. おかばな科（柳葉荣科）}

Circcea alpina L. ミヤマタニタデ 上益城郡大國見岳 C. erubescens Fr. et Sav. タニタラ゙ 入代郡五多庄藮木 C. quadrisulcata Fr. et Sav. ミッ゙タマサ ウ 飽託郡小萩山 Epilobium japonicum Haussk. イハアカバナ 八代郡五少生葉木

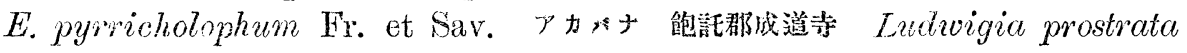

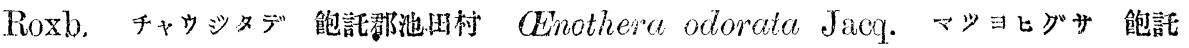
部黑䈠村

\section{Lythraceæ. みそはぎ程（个屈荣科）}

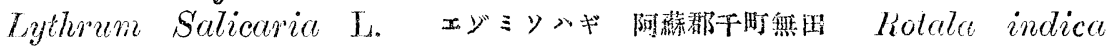
Koehne var. uliginosa Koehne. キカシグサ 能託郡黑筮村字室園 li. rotundifolic Koehne. 水ザキキカシグサ 饱託郡入景ノ宫附近

\section{Elaagnaces。ぐみ䔉（胡杼子科）}

Elcaunus glabra Thunb. ッッグミ 炎草都蒠阔 L. pungens Thunb. ナハシログミ熊本南內

\section{Thymelæaceæ. ぢんちゃうげ科（瑞否科）}

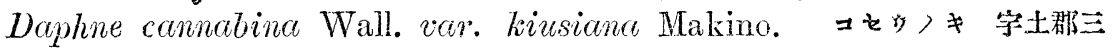

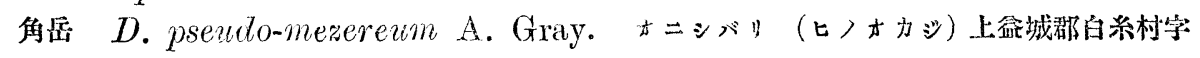
天主 Wikstromia Ganpi Maxim, コがンピ 天草郡福連森村

\section{Flacourtiaceæ.〈すごいげ科（柞木科）}

Idesia polycarpa Maxim. イ・ギり (ヤマギり)天草郡福連木村 Xylosma

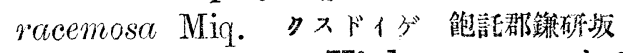

\section{Violaceæ. すみれ科 (等菜科)}

Viola liflora L。 キバナノコマノッメ 阿蘇山湯)谷上 V. Patrinii DC. var. chinensis Ging. ス $\Sigma$ 飽䚾郡本妙寺山 V. Sellirkii Pursh. forma major Maxim. ヨミヤマスミレ 下鱼城郡蕉让 V. sylvestris Kit. var. grypoceras Maxim. タヂリホスミレ 同上. $V$. verecunda A. Gray. ッホスミレ

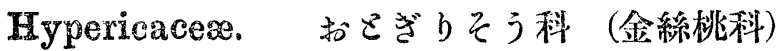

Hypericum chinense I. ビョウヤナギ 㐘地郡陣内村 H. erectum Thunb.

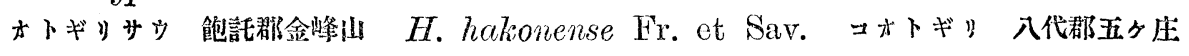

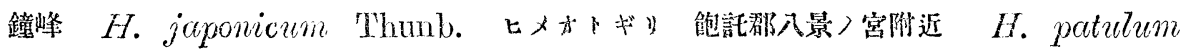
Thunb。 キンシバイ 能託郡活祄 